\title{
Violência conjugal: vivências expressas em discursos masculinos*
}

\author{
CONJUGAL VIOLENCE: EXPERIENCES EXPRESSED IN MALE DISCOURSES \\ VIOLENCIA ENTRE CÓNYUGES: EXPERIENCIAS EXPRESAS EN DISCURSOS MASCULINOS
}

\begin{abstract}
Normélia Maria Freire Diniz², Regina Lúcia Mendonça Lopes², Solange Maria dos Anjos Gesteira ${ }^{3}$, Sandra Lúcia Belo Alves ${ }^{4}$, Nadirlene Pereira Gomes ${ }^{5}$
\end{abstract}

\section{RESUMO}

Tendo como objeto a vivência de violência na relação conjugal, este estudo descritivo, de abordagem quali-quantitativa, teve como objetivo identificar a violência conjugal no discurso masculino. A população foi composta por 50 homens residentes na comunidade do Calafate, em San Martin, bairro localizado em Salvador/Ba. Para coleta de dados, utilizou-se entrevista com formulário semiestruturado. A amostra caracterizou-se por homens, na faixa etária entre 20 a 40 anos (74,0\%); convivendo conjugalmente $(98,0 \%)$. Com relação à violência conjugal, o índice encontrado foi de 80\%. Quanto às formas de violência, destacam-se a violência emocional e a violência física.

\section{PALAVRAS-CHAVE}

Maus-tratos conjugais. Violência na família. Violência

\author{
ABSTRACT \\ Aiming the research of \\ violence experiences in \\ conjugal relation, this \\ descriptive study, of qualitative \\ and quantitative approach, \\ aimed to identify conjugal \\ violence in male discourse. \\ Population was composed of \\ 50 men residing in Calafate \\ community, San Martin, a \\ quarter in Salvador/Ba. In \\ order to collect data, one \\ utilized the interview with \\ semi-structured formulary. \\ Sample was caracterized by \\ men between 20 and 40 years \\ old (74\%) cohabiting. \\ Concerning to conjugal \\ violence, we found an $80 \%$ \\ index. Relating to the forms of \\ violence, we've distinguished \\ emotional and physical \\ violence.
}

$\begin{array}{ll}\text { KEYWORDS } & \text { PALABRAS-CLAVE } \\ \text { Spouse abuse. } & \text { Maltrato conjugal. } \\ \text { Domestic violence. } & \text { Violencia doméstica } \\ \text { Violence. } & \text { Violencia } .\end{array}$

\section{RESUMEN}

Teniendo como objeto la experiencia de violencia en la relación entre cónyuges, este estudio descriptivo, de abordaje cuali-cuantitativo, tuvo como objetivo identificar la violencia entre cónyuges en los discursos masculinos. La población fue compuesta por 50 hombres residentes en la comunidad del Calafate, en San Martin, barrio ubicado en Salvador/Ba. Para colecta de los datos, se utilizó entrevista con formulario semiestructurado. La muestra se caracterizó por hombres de edad de 20 a 40 años (74,0\%), viviendo con la pareja (98,0\%0). Con relación a violencia entre cónyuges, el indice encontrado fue de 80,0\%. Cuanto a las formas de violencia, se destacan la violencia emocional y la violencia fisica.

Violencia.

\footnotetext{
* Recorte do projeto CNPq/ PIBIC - 2000 intitulado "Violência conjugal e suas implicações para prevenção de DSTs/ HIV: o discurso masculino"

1 Professora Adjunta do Departamento de Enfermagem Comunitária (DECOM) da Escola de Enfermagem da Universidade Federal da Bahia. Coordenadora do Projeto.

normelia@lognet.com.br

2 Professora Titular do DECOM. reginalm@cpunet.com.br

3 Professora Adjunta do DECOM. soso@svn.com.br

4 Enfermeira Obstétrica. Enfermeira do Ministério da Saúde no Programa PDIS em Natal. joadilson@digizap.com.br 5 Enfermeira do Fórum de Combate à Violência da Secretaria Municipal de Saúde - Juazeiro/Bahia. lenegomes@bol.com.br
} 
Normélia Maria Freire Diniz Regina Lúcia M. Lopes Solange Maria A. Gesteira Sandra Lúcia Belo Alves Nadirlene Pereira Gomes
(a)Dados obtidos através do Protocolo de Atendimento à Mulher em Situação de Violência, publicado no Jornal da Rede Saúde, 1999; 19:10-2.

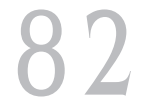

Rev Esc Enferm USP 2003; 37(2): 81-8.

\section{INTRODUÇÃO}

A violência aqui estudada refere-se à violência conjugal, enunciada como prática de tradição nos relacionamentos amorosos. Associada à violência doméstica, é caracterizada como violência de gênero, estando, sobretudo, presente nos cotidianos doméstico e conjugal das mulheres, mediante a definição do seu papel na sociedade.

A partir dos anos 80 , a situação de opressão da mulher na sociedade, nem sempre manifestada em sua forma de expressão mais trágica, qual seja, a violência física, passou a ser questionada pelos grupos feministas. Isso possibilitou a denúncia e o combate à violência contra a mulher que ocorria entre quatro paredes, nomeada de violência conjugal, e que, esporadicamente, chegava ao público através da imprensa que noticiava os crimes passionais. Tal combate foi determinante para a criação de Delegacias de Mulheres, muito estimulada pela influência de estudiosos de várias áreas do conhecimento.

No Brasil(a), as estatísticas disponíveis e os registros nas delegacias especializadas de crime contra a mulher, demonstram que $70 \%$ dos incidentes acontecem dentro de casa, sendo o agressor o próprio marido ou companheiro; mais de $40 \%$ das violências resultam em lesões corporais graves, decorrentes de socos, tapas, chutes, amarramentos, queimaduras, espancamentos e estrangulamentos.

Embora a violência conjugal esteja associada à lesões físicas, este fenômeno não se caracteriza apenas por uma gravidade clínica, mas, também, pelo seu impacto psicológico e social. Isto se explica pelo fato de que a violência nem sempre deixa marcas visíveis, haja vista, que esta é apenas uma das formas de expressão da violência conjugal, ou seja, a física $^{(1)}$.

Conforme a autora, a violência poderá também se expressar sob forma emocional (ameaças; chantagens; xingamentos; proibição à amizades ou visita à parentes), sexual (forçar a realizar relações sexuais ou tipos de atos sexuais; criticar o desempenho sexual) e por atos destrutivos (jogar fora ou destruir documentos pessoais; matar os animais de estimação). Isto, quase sempre, deixa marcas invisíveis, embora sua presença favoreça o desencadeamento de problemas para a saúde das mulheres envolvidas no cerco da vio- lência conjugal. A esse respeito, Oliveira ${ }^{(2)}$ afirma que a violência não necessariamente se inscreve no corpo apenas, mas, principalmente, na vida social e relacional.

Para Saffiotti, Almeida (3), as relações violentas tendem a obedecer uma escala progressiva durante os anos de relacionamento violento, iniciando com agressões verbais que passam para físicas e/ou sexuais, podendo chegar à ameaças de morte $\mathrm{e}$ homicídio.

Segundo Paiva ${ }^{(4)}$, alguns fatores podem desencadear situações de agressividade masculinas que, em muitos casos, encontramse interligados ou entrelaçados, tais como: problemas mentais, falta de diálogo entre $o$ casal, alcoolismo, dificuldades sexuais e fragilidade da auto-imagem.

$\mathrm{Na}$ perspectiva de gênero, homens e mulheres aprendem e internalizam, desde muito cedo, o seu sexo social. Isso se dá a partir de estereótipos culturais, que expressam o consenso generalizado de imagens atribuídas ao homem e à mulher. Socialmente, são exigidos, reproduzidos e naturalizados como próprios do comportamento masculino, a força, a agressividade, o destemor, enquanto que, ao contrário, às mulheres se exige a suavidade, a abnegação e a obediência. Isso determina uma hierarquia de desigualdades nas relações entre homens e mulheres, que se constituiu e institucionalizou historicamente em supremacia e dominação masculina, ao lado de inferiorização e subordinação feminina. A naturalização do comportamento agressivo e dos modos violentos, que parecem determinar a masculinidade, levam muitos homens a desconsiderarem os atos violentos, como tais os praticados em suas relações conjugais.

Todavia, na visão psicológica expressa por Nolasco ${ }^{(5)}$, a violência não se apresenta como uma marca dos homens, e chama a atenção para a existência de muitas relações entre homens e mulheres que não assumem a violência como um modo de funcionamento.

Para Ferreira ${ }^{(6)}$, a violência conjugal se manifesta em quatro modalidades: o homem que agride a mulher; a mulher que violenta o marido; os cônjuges que se agridem mutuamente; e os casais que, embora não sendo agressivos, cometem atos violentos quando não há mais consenso e comunicação entre os envolvidos. 
Contudo, estudos realizados no Brasil e no exterior mostram que, predominante, a vítima da violência conjugal é a mulher, e que esta sofre uma violência qualitativamente diferente da que a mulher pratica contra o homem $^{(7)}$. Assim, o incentivo social da agressividade como característica do masculino, explica porque o homem é o agressor em potencial e a mulher, a vítima.

Vale dizer que a maioria dos estudos referentes à temática violência conjugal traz entrevistas com mulheres. Contudo, uma relação de violência conjugal não envolve apenas as mulheres, tornado-se necessário, também, conhecer a fala do outro sujeito da relação: os homens. Neste contexto, o estudo tem como objetivo identificar a violência conjugal no discurso masculino.

\section{METODOLOGIA}

Trata-se de uma pesquisa descritiva com abordagem quali-quantitativa que teve como objeto de estudo a vivência de violência na relação conjugal.

O estudo foi realizado na comunidade do Calafate, locada no bairro soteropolitano de San Martin (Salvador/Ba), e teve o apoio do Coletivo de Mulheres do Calafate (CMC).

O CMC, entidade sem fins lucrativos criada em 1992, surgiu devido à alta incidência de violência doméstica na comunidade, o que viabilizou a escolha desta comunidade como cenário para realização deste estudo. Esta entidade vem sendo um espaço onde as mulheres, homens e adolescentes discutem os problemas relacionados ao seu cotidiano, sendo, desde 1997, locus de pesquisas e de atividades de extensão de estudantes de graduação e mestrado da Escola de Enfermagem da Universidade Federal da Bahia (EEUFBA).

A amostra foi composta por 50 (cinqüenta) homens residentes na referida comunidade, que participam de oficinas do Programa de Educação para Saúde do CMC. Estas oficinas contam com a participação de docentes e discentes da EEUFBA, integrantes do Grupo de Estudos sobre Saúde da Mulher (GEM), que fazem discussão de temas referentes à gênero, dentre os quais, gênero e saúde reprodutiva.
Após apresentação do projeto ao $\mathrm{CMC}$ e de sua aprovação, atendendo aos aspectos éticos, foi garantido aos participantes o anonimato e a livre decisão de participar do estudo. As entrevistas, agendadas conforme disponibilidade dos sujeitos, foram realizadas no turno da noite, nos dias úteis, no período de nov./1999 a fev./2000 na sede da Entidade. Cabe destacar o prévio preenchimento do termo de consentimento livre e esclarecido.

Como técnica de coleta de dados utilizou-se a entrevista com formulário (APÊNDICE A) contendo perguntas abertas e fechadas. $\mathrm{O}$ aspecto quantitativo contemplou variáveis sócio-demográficos: idade, religião, grau de escolaridade, estado civil, renda familiar, $n^{\circ}$ de pessoas/cômodos. As questões abertas, referentes à parte qualitativa, abordaram o entendimento de violência conjugal e a vivência de violência, incluindo sua(s) forma(s) de expressão.

Os dados resultantes das variáveis quantitativas foram armazenados em um banco de dados, através do programa computacional EPI-INFO 6.0, sendo, posteriormente, apresentados sob a forma de percentuais, ilustrados em Gráficos.

No tocante aos aspectos qualitativos, as falas foram gravadas e a análise teve como referencial teórico autoras(es) que trabalham a temática gênero e violência. Nesse sentido, o discurso masculino expressa a violência conjugal constituída conceitual-mente como aquela que se caracteriza física e sexualmente, sendo por eles justificada pela traição, pelo álcool e pela falta de dinheiro. Nesse sentido, o discurso masculino denota ser a violência conjugal expressa sob as formas física e sexual, sendo por eles justificada pela traição, pelo álcool e pela falta de dinheiro.

Tais situações acima destacadas constituíram as categorias identificadas através da técnica de análise temática. ${ }^{(8)}$ Foram realizadas as seguintes etapas: pré-análise, mediante exaustiva leitura; exploração do material que, consistiu na codificação, com o objetivo de alcançar o núcleo de compreensão do texto; recorte do texto em unidades de registro, e a etapa de classificação e de agregação dos dados, com a seleção de categorias que determinaram a especificação do tema, qual seja: violência conjugal.
Violência conjugal: vivências expressas em discursos masculinos 
Normélia Maria Freire Diniz Regina Lúcia M. Lopes Solange Maria A. Gesteira Sandra Lúcia Belo Alves Nadirlene Pereira Gomes

\section{APRESENTAÇÃOE DISCUSSÃO DOS RESULTADOS}

Neste trabalho identificamos, através dos discursos masculinos, a violência conjugal, abordando aspectos da violência no cotidiano da relação conjugal.

A amostra foi constituída por homens na faixa etária de 20 a 30 anos (40\%), seguida de 30 a 40 anos (34\%), apontando para a incidência de vivência de violência conjugal em jovens. Este dado corrobora com estudo realizado com mulheres com lesões corporais por violência conjugal atendidas em um serviço de Pronto-Socorro em Salvador/Ba, o qual revelou que $45,4 \%$ destas mulheres encontravam-se na faixa etária entre 21 e 30 anos e, portanto, também jovens ${ }^{(9)}$.

Assim sendo, a violência vivenciada por homens jovens, bem como por mulheres jovens, é destacada por Heise ${ }^{(10)}$ como uma vivência que é responsável por quase um ano perdido de vida saudável.

Quanto ao estado civil, 48\% dos homens declaram-se casados e 50\% solteiros, embora estes últimos convivam com companheiras. No que se refere ao grau de escolaridade, destacaram-se o $1^{\circ}$ grau incompleto $(30 \%)$ e $1^{\circ}$ grau completo (28\%), acompanhados dos seguintes percentuais: $2^{\circ}$ grau incompleto (16\%) e $2^{\circ}$ grau completo ( $\left.18 \%\right), 3^{\circ}$ incompleto $(2 \%), 3^{\circ}$ completo $(2 \%)$ e alfabetizado $(4 \%)$. A renda familiar esteve, predominantemente, na faixa de 1 a 5 salários mínimos (64\%). Os demais percentuais, ou seja, $16 \%, 6 \%$ e $14 \%$ ficaram distribuídos entre as demais rendas. Contudo, embora estes resultados mostram que os sujeitos têm baixa escolaridade e condições econômicas, sabemos que a violência não é determinada pela classe social ou grau de escolaridade.

Com relação ao conceito de violência conjugal, o Gráfico 1 mostra que 47,6\% dos homens entrevistados a percebem na forma de violência emocional, seguida da violência física, com 40,2\%. Estes dados diferem dos resultados apresentados em estudos com mulheres em situação de violência assistidas em maternidades do SUS, onde 60,6\% destas compreendem a violência conjugal enquanto violência física ${ }^{(11)}$.

A partir dos discursos dos homens entrevistados acerca da violência conjugal, tornouse possível identificar as formas de expressão, definida por Verardo ${ }^{(1)}$, as quais estão ilustradas através dos discursos masculinos:

\footnotetext{
Violência emocional : Proibir de fazer algo: amizade e chegar tarde; xingamentos, palavras que machucam;

Violência física: Bater na cara dela, deixar marcas no corpo e até sangrar, murro, sai até na mão, tijolada, porrada;

Violência sexual: Forçar a mulher agressivamente ao ato sexual e tipo de ato; pegar a pulso quando ela não quer transar;e

Violência por atos destrutivos: Quebrando as coisas dentro de casa, jogar as coisas dela fora ou rasgar.
}

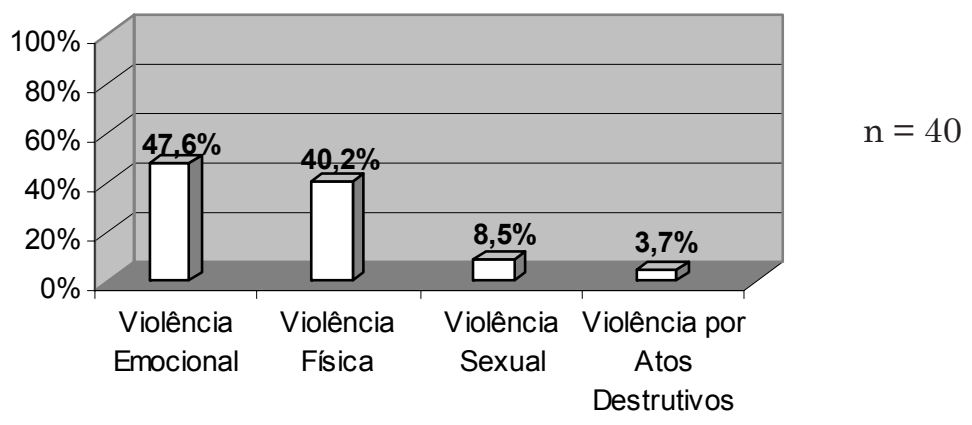


No que se refere ao aspecto qualitativo, a representação da violência se expressa nos discursos masculinos a seguir, que foram organizados nas categorias:

Traição: O homem trair a mulher, ela saber; mulher trair o homem ele quer matar também.

A traição aqui representada está centrada na organização social de gênero, que determina a imagem do homem e da mulher. Segundo Nolasco ${ }^{(12)}$, os homens crescem sendo incentivados a enganar a mulher e, ao mesmo tempo, a desenvolver atitudes agressivas, de modo a evitar o contrário. A hipótese de traição, os deixa desmoralizados, o que leva à reações violentas.

Violência sexual: Para mim, violência
conjugal é quando o marido maltrata a
mulher através do relacionamento se-
xual, às vezes a mulher não quer prati-
car sexo naquele momento que ele de-
seja e aí surge a violência.

Violência física: O negócio de homem é querer bater mesmo, agressão, mulher é mais na conversa, agredir nas palavras, mas o homem não, é machão, o poderoso, ele quer sempre agredir fisicamente.

Analisando as categorias citadas, apoiamo-nos em Nolasco ${ }^{(13)}$. O autor afirma que o comportamento masculino, mesclado na intimidade com o sexo e a violência, está previsto no ideal de masculinidade vigente na sociedade, que ao ser estimulado pode levar os meninos a confundirem a violência com atividade e iniciativa de vida, vindo a dominar a mulher.

Uso do Álcool: ... talvez seja até a bebida, o cara bebe demais, se altera no álcool e chega em casa, aí dispara para a mulher e a;i começa aquele atrito os dois.

Soares ${ }^{(14)}$ afirma que os próprios profissionais e militantes contra a violência refutam a hipótese de uma relação causal, uma vez que ambos são, simultaneamente, motivados por combinações de fatores sócio-econômicos e culturais, além de não estarem limitados a nenhum grupo social em particular. Segundo a autora, alguns estudos indicam que a violência está mais relacionada à aceitação da legitimidade do comportamento violento do que à bebida, isoladamente.
Falta de dinheiro: Às vezes, tá faltando dinheiro e a mulher não compreende aquele momento difícil que está passando, aí a violência aparece.

Consideramos que embora as questões de pobreza não expliquem a violência, haja vista a sua presença em todas as classes sociais, elas são, via de regra, desenca-deadoras de situações conflituosas. Saffioti ${ }^{(3)}$ salienta que o papel do provedor do lar, atribuído ao homem, constitui um pesado fardo, pois, quer ele seja o único provedor da família ou o principal, não lhe é permitido falhar.

Alves ${ }^{(15)}$ traz a preocupação com o possível contingente de homens que, se tornam violentos para com sua família, em decorrência do desemprego, e que se apóiam no álcool após se desesperarem frente ao não surgimento de uma atividade laboral.

É importante considerar que ao referir o que é violência, os entrevistados retratam exatamente as expressões identificadas nos estudos com mulheres em situações de violência conjugal. Tal fato pôde ser evidenciado na pesquisa com mulheres residentes no Calafate, mesmo locus onde foi desenvolvido este estudo, a qual revelaram situações de violência conjugal, tais quais: Violência emocional - acusação de ter amantes, xingamentos, impedimentos de manter amizades, humilhações publicas; Violência física - chutes, empurrões, tapas; Violência sexual - relações sexuais forçadas, críticas ao desempenho sexual; e Violência por atos destrutivos - revirar a casa, jogar pertences na rua, esconder objetos e documentos pessoais, quebrar móveis, destruir roupas. ${ }^{(16)}$

Um outro ponto importante a ser observado quando os homens conceituam violência, é a condição de agressor do homem e a situação de vítima da mulher. Essa visão é fruto de uma construção social de gênero, interiorizada naturalmente a partir de relações socais e permeada pelo poder masculino. Observa-se que as falas trazem o homem como o agressor, traduzindo a construção masculina organizada desde o olhar, a forma de pensar e o sentir masculino, constituintes do modelo patriarcal, a partir do qual é interiorizado naturalmente na sociedade, o poder pelo homem e a opressão pela mulher.
Violência conjugal:

vivências expressas em discursos masculinos 
Normélia Maria Freire Diniz Regina Lúcia M. Lopes Solange Maria A. Gesteira Sandra Lúcia Belo Alves Nadirlene Pereira Gomes
No que diz respeito à vivência de violência na relação conjugal, $80 \%$ dos homens entrevistados referiram vivenciá-la no seu cotidiano conjugal, sendo esta praticada nas suas diversas formas de expressão (violência emocional, física, sexual e por atos destrutivos), em semelhantes proporções tanto pelo companheiro como pela companheira, como mostra o Gráfico 2. Este resultado assemelha-se aos encontrados em estudos realizados com mulheres na mesma comunidade $(92,4 \%)$ e em duas Maternidades Públicas $(86,0 \%$ e $73,0 \%)$ de Salvador ${ }^{(17-18)}$.

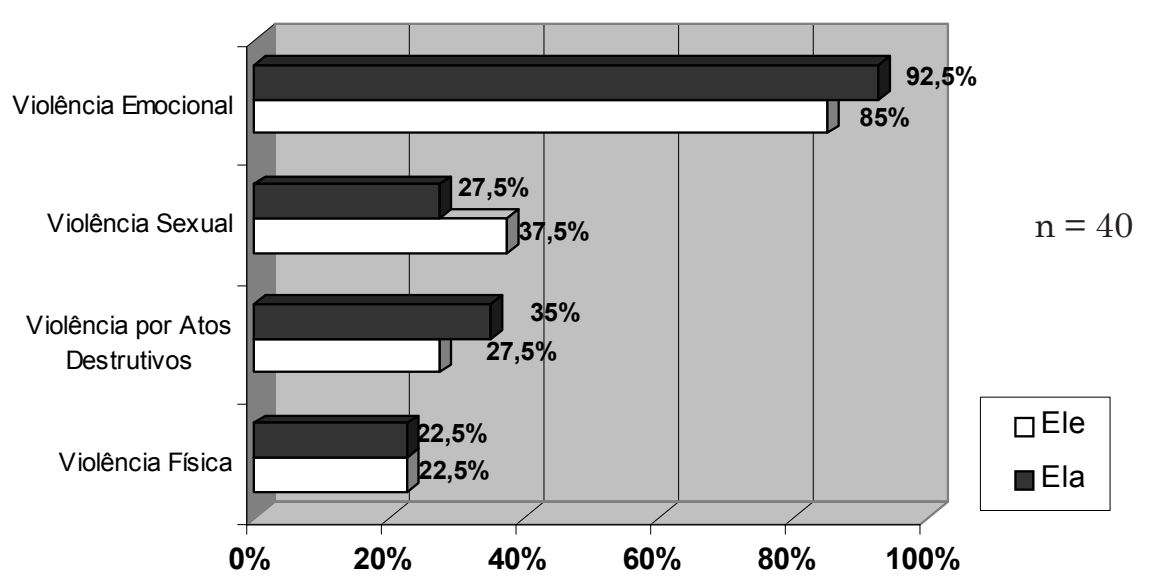

Gráfico 2 - Homens da comunidade do Calafate. Salvador/2000. (Formas de Violência Conjugal praticadas pelo companheiro e companheira.)

Os resultados demonstram que, embora o homem represente o masculino como agressor na relação conjugal, ao mesmo tempo ele aponta a mulher, em proporções semelhantes, também como agressora. Isto nos leva a questionar se este resultado que aponta a mulher como praticante da violência em semelhante proporção ao masculino, representaria o que se conceitua como violência numa relação, o que segundo Chauí ${ }^{(19)}$ se apresenta como uma ação que trata o ser humano não como sujeito, mas como uma coisa, negando-lhe a possibilidade de ser sujeito, de construir-se e constitui-se como capaz de autonomia na relação.

\section{CONSIDERAÇÕES FINAIS}

Os dados deste estudo nos mostram que o masculino apresenta percentuais de vivência de violência conjugal semelhantes aos encontrados em estudos com mulheres.
No que diz respeito ao sujeito da agressão, o masculino e o feminino encontram-se nas mesmas proporções, embora os homens tenham representado a violência conjugal como uma expressão a eles inerente.

Sem dúvida, o enfoque do masculino é indispensável para a compreensão da dinâmica que envolve as relações violentas entre homens e mulheres, pois permitiu trabalhar com o outro lado da relação conjugal, até então pouco valorizado, já que a maioria dos trabalhos desenvolvidos com o tema aborda o discurso feminino. Esse deslocamento de enfoque torna-se importante, pois proporciona pensar, também, em estratégias de conhecimento e intervenção que considerem os homens, fazendo com que agressores e agredidas pensem numa relação mais solidária e eqüitativa. 
(1) Verardo MT. Violência no relacionamento “amoroso". São Paulo:IMEP; 1990. (série Violência e Gênero).

(2) Oliveira FA. Violência contra a mulher é uma questão de saúde pública. Jornal da redesaúde 1999; 19(10).

(3) Saffioti HIB, Almeida SS. Violência de gênero: poder e impotência. Rio de Janeiro: Revinter; 1995.

(4) Paiva JR. Mulheres espancadas [online] 1999.Disponível em: http://www. members. tripod.com/soswomen/paget.html.> (24nov. 1999).

(5) Nolasco S. O peso da cultura. Rev Maria Maria 1999; 1( 0): 24-5.

(6) Ferreira GB. La mujer maltratada: un estudio sobre las mujeres víctimas de la violencia doméstica. $2^{\text {nd }}$. Buenos Aires: Sudamericana; 1994.

(7) Soares BM. O que acontece com as mulheres que apanham dos maridos? [online]. Disponível em: http://www.cfch.ufrj.br/jor_pesq/ Violenc/saffioti.html $>$ (30 nov.2001).

(8) Bardin L. Análise de conteúdo. Lisboa: Setenta; 1997.

(9) Rodrigues AD, Diniz NMF. Assistência à mulher: reconhecendo lesões corporais como indícios de violência doméstica. Salvador:EE/ UFBA; 2001.[Relatório de pesquisa - CNPqPIBIC].

(10) Heise L, Pitanguy J, Germain A . Violencia contra la mujer: carga de salud oculta. Washington DC: Banco Mundial; 1993. (mimeografado).
(11) Diniz NMF. Prevenção das DSTs/HIV e violência conjugal. [ apresentado ao II Encontro de Pesquisa em Enfermagem da Bahia, 1999. Salvador]

(12) Nolasco S. O mito da masculinidade. $2^{\text {nd }}$ ed. Rio de Janeiro: Rocco; 1995.

(13) Nolasco S. Um homem de verdade. In: Caldas D, organizador. Homens. São Paulo: SENAC; 1997.

(14) Soares BM. Mulheres invisíveis: violência conjugal e novas políticas de segurança. Rio de Janeiro: Civilização Brasileira; 1999.

(15) Alves SSB. Violência conjugal: representações masculinas. [dissertação] Salvador (BA): Escola de Enfermagem da Universidade Federal da Bahia; 2000.

(16) Diniz NMF, Lopes RLM, Almeida MS, Alves SLB, Matos MEC, Couto IM. Saúde da mulher: violência intra-familiar e suas repercussões no auto-cuidado. Texto Contexto Enferm 1999; 8(2):436-9.

(17) Diniz NMF. A mulher sob o signo da violência doméstica e institucional nos serviços de saúde. Salvador:EE/UFBA; 2000. [ Relatório de pesquisa - Fundação Ford]

(18) Diniz NMF, Alves SL, Gomes NP. Violência conjugal e suas implicações para prevenção de DSTs/HIV: o discurso masculino. Salvador:EE/UFBA; 2000. [Relatório de Pesquisa - CNPq - PIBIC]

(19) Chauí M. Perspectivas antropológicas da mulher. Rio de Janeiro: Zahar; 1985.
Violência conjugal: vivências expressas em discursos masculinos 
Normélia Maria Freire Diniz Regina Lúcia M. Lopes Solange Maria A. Gesteira Sandra Lúcia Belo Alves Nadirlene Pereira Gomes

\section{APÊNDICE}

INSTRUMENTO DE COLETADE DADOS

\section{I - DADOS SÓCIO-DEMOGRÁFICOS: \\ 1.1 - Idade: anos. \\ 1.2 - Religião: \\ 1.3 - Grau de escolaridade: \\ ( ) Nunca estudou \\ ( )Alfabetizado \\ ( ) Primeiro grau incompleto \\ ( ) Primeiro grau completo \\ ( ) Segundo grau incompleto \\ ( ) Segundo grau completo \\ ( ) Superior incompleto \\ ( ) Superior completo}

1.4 - Estado civil:
( ) Casado
( ) Solteiro
( ) Viúvo
( ) Desquitado, divorciado ou separado

1.5 - Renda familiar: salários mínimos

$1.6-$ N. ${ }^{\circ}$ pessoas:

1.7 - N. ${ }^{\circ}$ cômodos:

II - O QUE É VIOLÊNCIA ENTRE MARIDO E MULHER?

III - VOCÊ SOFRE VIOLÊNCIA NO RELACIONAMENTO COM SUA COMPANHEIRA? Se SIM, como isso se dá? 